\title{
How do Features of Electronic Health Records Impact Prescription of Nicotine Replacement Therapy?
}

\author{
Thomas English \\ University of Alabama \\ tmenglish1@cba.ua.edu \\ Daniel Amante \\ UMass Medical School \\ daniel.amante@umassmed.edu \\ Erin Borglund \\ UMass Medical School \\ erin.borglund@umassmed.edu
}

\author{
Ariana Kamberi \\ UMass Medical School \\ ariana.kamberi@umassmed.edu \\ Rajani Sadasivam \\ UMass Medical School \\ rajani.sadasivam@umassmed.edu \\ Rebecca Kinney \\ UMass Medical School \\ rebecca.kinney@umassmed.edu
}

\author{
Thomas Houston \\ UMass Medical School \\ thomas.houston@umassmed.edu
}

\begin{abstract}
Nicotine Replacement Therapy (NRT) is an effective medication to help patients quit smoking tobacco. Yet, $18 \%$ of adults in the United States still smoke cigarettes. With advancements in health technology and improved features within electronic health record (EHR) systems, it is crucial to understand how differences in EHR features influence the prescribing of NRT. We conducted a cross-sectional study of 174 primary care practices to better understand how EHR features, including drug reference databases in EHRs, were associated with NRT prescribing at a practice level. Regression models were created to understand NRT prescribing patterns among clinics with varying EHR features and found that practices using an EHR with a drug reference database were 2.3 times more likely to view NRT as a high priority for treating smokers. Use of NRT in primary care differs significantly in relation to the capability of a clinic's technology. Clinics with more EHR features, specifically EHR drug reference databases, favored NRT. Our study suggests that pharmacotherapy could become the preferred activity in smoking cessation treatment, as EHR-integrated drug reference database prevalence increases.
\end{abstract}

\section{Introduction}

Smoking is the number one preventable cause of premature death in the United States. While prevalence of tobacco use has declined over the past few decades, 17\% (40 million people) of Americans are still addicted to smoking cigarettes.[17] Of those that do attempt to quit, only $5 \%$ will successfully maintain cessation at 6 months.[1] Helping smokers quit is the most important action that healthcare providers can take to improve the length and quality of life of these patients.[8] Since the majority of smokers (70\%) see a healthcare provider at least once annually,[3, 6, 7, 13, 22] the point of care encounter is an ideal time to address smoking cessation. Nicotine Replacement Therapy (NRT) is defined as a smoking cessation treatment where nicotine from tobacco is replaced by other forms of pharmaceutical nicotine, such as through the skin with patches, inhalation of sprays, or consumed using gum or lozenges.[21] NRT is an effective method for smoking cessation[20] and thus, Clinical Practice guidelines recommend NRT to assist patients in their cessation efforts.[4] However, despite the Clinical Practice guidelines, only a small percentage of smokers receive NRT from their healthcare provider.[11]

Electronic Health Records (EHRs) offer an opportunity to increase quality of care delivered at the system-level in outpatient settings. EHRs, which are now common in outpatient settings,[12] provide a means to improve cessation through effective documentation and tracking of clinical practice. For example, physician reminder systems incorporated into EHRs have demonstrated their efficiency in various settings to increase preventive service.[2, 16] Recent Meaningful Use regulations through the EHR Incentive Program administered by the Centers for Medicare \& Medicaid Services (CMS) mandate health professionals and physicians electronically screen for tobacco use in their patients.[18] Under such guidelines, EHRs offer the opportunity for health care providers and patients to be better able to coordinate care and share health information, 
particularly regarding preventable medical conditions. However, the implementation of EHRs in the United States is still varied.[9] Of those practices with EHR systems, there are wide variations in the implementation and adherence to standard prevention guidelines.[23]

The potential to show that EHR-integrated features improve smoking cessation treatment has been limited thus far. ${ }^{[15]}$ EHR-integrated Electronic Drug Reference Databases provide healthcare providers with critical information at the point-of care[14] and can be used in congruence with other EHR-integrated decision support tools to assist in NRT prescribing. To the authors' knowledge, this is the first study to investigate the association of electronic health record features, specifically electronic drug reference databases integrated into EHRs, with the prescription of NRT.

\section{Methods}

\subsection{Study Design}

In preparation for a national technologyassisted clinical microsystem tobacco control implementation trial,[10] we conducted a crosssectional survey of primary care practices. This survey assessed both EHR implementation and tobacco control activities. This study was reviewed and approved by the University of Massachusetts Medical School Institutional Review Board.

\subsection{Setting and Sample}

One hundred seventy-four medical practices, nationwide, were recruited from a registered database of internal medicine and family practice clinics. These practices were recruited for two federallyfunded pragmatic trials evaluating Decide2Quit.org, a patient-centered web-assisted tobacco intervention and QUIT-PRIMO (Quality Improvement in Tobacco Provider Referrals \& Internet-delivered Microsystem Optimization). ${ }^{[10]}$ For our study, we utilized the baseline practice-level surveys from both of the aforementioned trials in our analyses.

\subsection{Data Collection}

A mailed survey of five pages was completed by each practice. Practices were asked to identify a single point of contact (physician or nurse), who would complete the data collection for the practice. The survey contained questions about clinic characteristics and about patient tobacco assessment and treatment activities. Questions were formatted as either dichotomous closed-ended questions or questions with a Likert scale response. Practice respondents identified their role and provided information related to perceived barriers, use of tools, and subsequent guideline-concordant tobacco control activities. Practices were also asked to report their current level of EHR adoption.

Independent Variables. Electronic Health Record (EHR) utilization was captured by the baseline survey using a yes/no response. Additionally, we asked if electronic decision support systems or drug reference databases were used. These questions also had dichotomous response categories. To estimate patient panel age, we asked practices to report the approximate percentage of patients in the clinic that fall in following age ranges: $1-18,19-44,45-64,65$ or older. To estimate patient panel race, we asked practices to report the approximate percentage of patients in their clinic that are the following races: White, Black, Hispanic, American Indian, Asian or Pacific Islander, and Other (please specific). To estimate patient panel insurance, we asked practices to report the approximate percentage of patient care revenue received from the following sources: Captitated or prepaid basis (commercial), capitated or prepaid bases (state or federal), fee for service third party payer, self-pay, charity care, other (please specify).

Additional characteristics of the clinics were ascertained by asking approximately how many patients are seen at the practice per week? What the estimated daily number of incoming calls to the practice from patients was? How many computers with Internet access does this practice have? And if the practices were internal medicine clinics or family medicine practices.

Dependent Variable. The dependent variable of interest was if prescribing NRT was included in tobacco control activities. Participants were asked to rate their agreement with the statement below using a five-point Likert scale ranging from strongly agree to strongly disagree to form our dependent variable:

"Prescribing nicotine replacement therapy for patients ready to quit IS a high priority for our practice.”

\subsection{Statistical Analyses}

We used a logistic regression model to evaluate what technological capabilities were associated with a prioritization of NRT.

For the dependent variable, viewing prescribing of NRT as a high priority,, the 5-point Likert scale results were recoded into a dichotomous variable due to a low percentage of answers in some response categories. We placed practices that strongly agreed and agreed with the statement in one 
group and the remainder of the practices in a second group.

\section{Results}

\subsection{NRT Emphasis}

Of the 174 practices who returned the practice-level surveys, 106 viewed NRT as a high priority while 68 did not. We compared the characteristics of practices that saw NRT as a priority vs. those that did not. We found no statistically significant differences in patient population, payer mix, clinic volume, and practice type. Comparisons are shown in Table 1.

Table 1.

\begin{tabular}{|c|c|c|c|}
\hline & $\begin{array}{l}\text { NRT } \\
\text { not a } \\
\text { Priority } \\
\mathrm{n}=68\end{array}$ & $\begin{array}{l}\text { NRT a } \\
\text { Priority } \\
n=106\end{array}$ & $\begin{array}{l}\text { Sig. } \\
(2- \\
\text { tailed) }\end{array}$ \\
\hline \multicolumn{4}{|l|}{ Patient Panel Age (\%) } \\
\hline 1-18 Years & 9.6 & 9.7 & 0.92 \\
\hline 19-44 Years & 28.5 & 27.6 & 0.61 \\
\hline 45-64 Years & 33.6 & 34.7 & 0.50 \\
\hline $65+$ Years & 28.8 & 27.9 & 0.68 \\
\hline \multicolumn{4}{|l|}{ Patient Panel Race (\%) } \\
\hline White & 72.7 & 72.2 & 0.59 \\
\hline Black & 19.9 & 21.6 & 0.60 \\
\hline Hispanic & 12.3 & 15.4 & 0.30 \\
\hline Other Race & 7.8 & 6.1 & 0.34 \\
\hline \multicolumn{4}{|l|}{$\begin{array}{l}\text { Patient Panel Insurance } \\
(\%)\end{array}$} \\
\hline $\begin{array}{r}\text { Capitated or Prepaid } \\
\text { Commercial }\end{array}$ & 16.5 & 20.6 & 0.23 \\
\hline $\begin{array}{r}\text { Capitated or Prepaid } \\
\text { State or Federal }\end{array}$ & 30.6 & 29.2 & 0.67 \\
\hline Fee for Service & 40.2 & 37.4 & 0.55 \\
\hline Self-Pay & 9.8 & 9.2 & 0.79 \\
\hline Charity Care & 3.9 & 4.4 & 0.75 \\
\hline Other Insurance & 1.0 & 2.3 & 0.44 \\
\hline \multicolumn{4}{|l|}{$\begin{array}{l}\text { Clinic Characteristics } \\
\text { (mean) }\end{array}$} \\
\hline $\begin{array}{r}\text { Visits per week per } \\
\text { provider }\end{array}$ & 98.4 & 102.3 & 0.63 \\
\hline Daily calls from patients & 54.8 & 61.6 & 0.50 \\
\hline $\begin{array}{r}\text { Number of computers } \\
\text { per practice }\end{array}$ & 4.9 & 4.4 & 0.45 \\
\hline $\begin{array}{r}\text { Type of Practice (\%) } \\
\text { Internal Medicine } \\
\text { Family Medicine }\end{array}$ & $\begin{array}{l}50.0 \\
50.0\end{array}$ & $\begin{array}{l}40.0 \\
60.0\end{array}$ & 0.14 \\
\hline
\end{tabular}

\subsection{Logistic Regression}

The logistic regression model (Table 2) including having any Electronic health record, having an EHR with a decision support system, and having an EHR that includes and drug reference database. This model shows that practices with a drug reference database were $2.34(p=0.03)$ times more likely to prioritize NRT than practices without a drug reference database included in the EHR. In addition to this primary model, we conducted sensitivity analyses including characteristics in Table 1, with no change in the main effect, and there were no other significant associations.

Table 2. Logistic Regression predicting factors associated with viewing NRT as a high priority.

\begin{tabular}{|c|c|c|c|c|}
\hline & $\begin{array}{l}\text { Odds } \\
\text { Ratio }\end{array}$ & $\mathrm{B}$ & S.E. & Sig. \\
\hline $\begin{array}{l}\text { Clinic has Decision } \\
\text { Support System } \\
\text { integrated with the EHR }\end{array}$ & 1.8 & 0.58 & 0.47 & 0.22 \\
\hline $\begin{array}{l}\text { Clinic has any } \\
\text { Electronic Health } \\
\text { Record }\end{array}$ & 1.0 & 0.01 & 0.36 & 0.97 \\
\hline $\begin{array}{l}\text { Clinic has Drug } \\
\text { Reference Database } \\
\text { integrated with the EHR }\end{array}$ & 2.3 & 0.85 & 0.38 & 0.03 \\
\hline Constant & 0.8 & -0.24 & 0.64 & 0.71 \\
\hline
\end{tabular}

\section{Discussion}

In a cross-sectional study of 174 primary care practices recruited from our nationwide study, we found that practices with electronic drug reference databases integrated into electronic health record systems were more likely to prioritize NRT than practices without drug reference databases. Our findings indicate that drug reference databases are a critical component of the EHR because they notify providers of important health interventions, in this case NRT. Drug reference databases have the potential to be an integral part of efficient decision support for health behavior outcomes. Despite research that suggests a combination of NRT and therapy in smoking cessation treatment,[19] current EHR decision support systems primarily focus on medication, especially EHRs with a drug reference database. Providers using EHRs and drug reference databases may get prompts and support in recommending medicinal interventions, but not 
evidence-based behavioral interventions. Future considerations for software rollouts should integrate decision support tools focusing on behavioral strategies with drug reference databases.

As EHRs continue to be implemented throughout the nation, it is likely that the benefits of more complex system components will be actualized. EHR comprehensive decision support for smoking cessation has the potential to increase primary prevention and the quality of life of patients by addressing all five stages of the 5 A's of smoking cessation guidelines: ask, advise, assess, assist, and arrange.[5] Given the frequency in which individuals visit their primary care providers, EHRs present an effective mode in which to support tobacco cessation among patient populations.

This study was limited to a small sample of clinics participating in a smoking cessation study, and therefore may not be generalizable to the broader population. It should also be noted that EHR capabilities and the smoking cessation treatment information were self-reported by the practices, which introduces the risk of misclassification bias. Still, these findings provide a foundation in which to generate further hypotheses, interventions, and research in the realm of EHRs and practice-based smoking cessation efforts.

\section{Conclusion}

Use of NRT in primary care differs significantly in relation to the capability of a clinic's use of technology. Clinics with more technological capabilities, specifically those with drug reference databases, favored NRT. Our study suggests that pharmacotherapy could become the preferred activity in smoking cessation treatment, as drug reference database prevalence increases. Past studies have looked at EHRs as a general tool to support smoking cessation, and not specific features, and systematic reviews have noted that only weak evidence exists. Thus, our work adds to literature by identify drug databases as the specific feature related to treatment with NRT. Future studies should attempt to address how technology can be used more effectively in smoking cessation and other preventive activities in larger patient populations.

\section{Acknowledgements}

This work was supported by the National Cancer Institute (1R01CA129091 and 1UL1RR031982-02).

\section{References}

1. Blak, B.T., K. Wilson, M. Metcalfe, et al., Evaluation of varenicline as an aid to smoking cessation in UK general practice - a THIN database study. Curr Med Res Opin, 2010. 26(4): p. 861-70.

2. Department of Veterans Affairs, O.o.E.D., VistAHealtheVet Monograph 2008-2009. 2008: p. 1146.

3. Eckert, T. and C. Junker, Motivation for smoking cessation: what role do doctors play? Swiss Med Wkly, 2001. 131(35-36): p. 521-6.

4. Fiore, M., Bailey, WC, Cohen, S, et.al. , Treating Tobacco Use and Dependence: Clinical Practice Guideline 2008 Update. US Department of Health and Human Service, Public Health Service, Agency for Health Care Policy and Research, 2008(2008): p. 37.

5. Fiore, M.C., W.C. Bailey, S.J. Cohen, et al., Treating tobacco use and dependence: clinical practice guideline. Rockville, MD: US Department of Health and Human Services, 2000: p. 00-0032.

6. $\quad$ Fiore, M.C., R.T. Croyle, S.J. Curry, et al., Preventing 3 million premature deaths and helping 5 million smokers quit: a national action plan for tobacco cessation. Am J Public Health, 2004. 94(2): p. 205-10.

7. Fiore, M.C. and C.R. Jaen, A clinical blueprint to accelerate the elimination of tobacco use. JAMA, 2008. 299(17): p. 2083-5.

8. Fiore, M.C., D.E. Jorenby, and T.B. Baker, Smoking cessation: principles and practice based upon the AHCPR Guideline, 1996. Agency for Health Care Policy and Research. Ann Behav Med, 1997. 19(3): p. 213-9.

9. Hillestad, R., J. Bigelow, A. Bower, et al., Can electronic medical record systems transform health care? Potential health benefits, savings, and costs. Health Aff (Millwood), 2005. 24(5): p. 1103-17.

10. Houston, T.K., R.S. Sadasivam, D.E. Ford, et al., The QUIT-PRIMO provider-patient Internetdelivered smoking cessation referral intervention: a cluster-randomized comparative effectiveness trial: study protocol. Implement Sci, 2010. 5: p. 87.

11. Huang, Y., J. Britton, R. Hubbard, and S. Lewis, Who receives prescriptions for smoking cessation medications? An association rule mining analysis using a large primary care database. Tob Control, 2013. 22(4): p. 274-9.

12. Jamoom, E. and E. Hing, Progress with electronic health record adoption among emergency and outpatient departments: United States, 2006-2011. NCHS Data Brief, 2015(187): p. 1-8.

13. Lancaster, T. and L.F. Stead, Self-help interventions for smoking cessation. Cochrane Database Syst Rev, 2005(3): p. CD001118. 
14. Maki, S.E. and B. Patterson, Using the ELectronic Health Record in the Health Care Provider Practice. 2013, Cengage Learning: Clifton Park, NY.

15. Mathias, J.S., A.K. Didwania, and D.W. Baker, Impact of an electronic alert and order set on smoking cessation medication prescription.

Nicotine Tob Res, 2012. 14(6): p. 674-81.

16. Network, T.H.C.R. CAPACITY, COLLABORATION, AND INVESTIGATION. 2010; Available from: http://crn.cancer.gov.

17. Prevention, C.f.D.C.a. Current Cigarette Smoking Among Adults in the United States. Smoking \& Tobacco Use 2015 December 8, 2015; Available from:

http://www.cdc.gov/tobacco/data_statistics/fact_s heets/adult_data/cig_smoking/.

18. Rabius, V., M. Karam-Hage, J.A. Blalock, and P.M. Cinciripini, "Meaningful use" provides a meaningful opportunity. Cancer, 2014. 120(4): p. 464-8.

19. Stead, L.F. and T. Lancaster, Combined pharmacotherapy and behavioural interventions for smoking cessation. Cochrane Database Syst Rev, 2012. 10: p. CD008286.

20. Stead, L.F., R. Perera, C. Bullen, et al., Nicotine replacement therapy for smoking cessation. Cochrane Database Syst Rev, 2012. 11: p. CD000146.

21. Stead, L.F., R. Perera, C. Bullen, et al., Nicotine replacement therapy for smoking cessation. The Cochrane Library, 2008.

22. Strecher, V.J., Computer-tailored smoking cessation materials: a review and discussion. Patient Educ Couns, 1999. 36(2): p. 107-17.

23. Vogt, T.M., A.C. Feldstein, M. Aickin, et al., Electronic medical records and prevention quality: the prevention index. Am J Prev Med, 2007. 33(4): p. 291-6. 